\title{
Net contribution of spillover from a marine reserve to fishery catches
}

\author{
Raquel Goñi ${ }^{1, *}$, Ray Hilborn ${ }^{2}$, David Díaz ${ }^{1}$, Sandra Mallol ${ }^{1}$, Sara Adlerstein ${ }^{3}$ \\ ${ }^{1}$ Centro Oceanográfico de Baleares, IEO, Muelle de Poniente s/n, 07015 Palma de Mallorca, Spain \\ ${ }^{2}$ School of Aquatic and Fishery Sciences, PO Box 355020, University of Washington, Seattle, Washington 98195, USA \\ ${ }^{3}$ School of Natural Resources and Environment, University of Michigan, 3010 Dana Building, Ann Arbor, Michigan 48109-1115, USA
}

\begin{abstract}
Benefits for fisheries from marine protected areas (MPAs) are expected from recruitment of exported eggs and larvae as well as from spillover of adults to adjacent fishing grounds. Because the recruitment effect is difficult to detect, spillover is presently the only tangible potential fishery benefit of MPAs. Despite abundant evidence of spillover in the literature, this is the first study to quantify the number and biomass of individuals annually spilling over from an MPA and their contribution to the local fishery catches. Using a decade (1997-2007) of tag-recapture data for the lobster Palinurus elephas from the Columbretes Islands Marine Reserve (CIMR), we estimated annual emigration probabilities of $3.7 \%$ (female) and $6.7 \%$ (male), and quantified the resulting spillover to adjacent fished areas. We showed that during an 8 to $17 \mathrm{yr}$ protection period, harvested spillover offset the loss of yield resulting from the reduction of fishing grounds set aside in the CIMR, producing a mean annual net benefit of $10 \%$ of the catch in weight. Although the number of lobsters spilling over annually did not quite make up for the loss of fishing grounds in the CIMR, it did in weight because the mean size of the lobsters emigrating from the reserve was larger than that of those outside. We propose that nomadic or home range movements of individuals near MPA boundaries, seasonal migrations and migrations forced by extraordinary meteorological events, and density-dependent movements facilitated spillover from the CIMR. Fishing effort concentration along its boundaries and high exploitation rates in the local fishery limited the spatial extent of spillover.
\end{abstract}

KEY WORDS: Marine reserve - Marine protected area · Spillover • Adult emigration . Fishery benefits · Commercial catch · Dispersion imbalance · Competitive exclusion - Lobster • Artisanal fisheries

Resale or republication not permitted without written consent of the publisher

\section{INTRODUCTION}

In recent years, a plethora of studies have been concerned with assessing the benefits of marine protected areas (MPAs) on exploited species, many of them documenting increases in abundance, biomass, individual size and egg production inside MPAs following the reduction or cessation of fishing (e.g. Sánchez-Lizaso et al. 2000, Russ 2002, Claudet et al. 2010). While there is general agreement about their conservation benefits, attention to the effects of MPAs on fisheries has grown particularly controversial (Hilborn et al. 2004), primarily due to the scarcity of evidence documenting their efficacy (Willis et al. 2003, Hilborn 2006) and con- cern about loss of fishing grounds (Jones 2008). Contributions to this question may come from empirical or theoretical studies. Empirical studies generally evaluate the potential MPA benefits of spillover (net export of juveniles/adults: Russ 2002) to adjacent fisheries based on field data, typically obtained from onboard sampling or landings, experimental fishing, tagrecapture or underwater censuses (e.g. McClanahan \& Mangi 2000, Goñi et al. 2006, Tupper 2007, Forcada et al. 2009). Alternatively, theoretical modeling studies simulate fishery impacts of MPAs under different MPA configurations, recruitment or connectivity scenarios, or adult mobility and exploitation rates (e.g. Polacheck 1990, Acosta 2002, Walters et al. 2007, to name some 
that account for movement dynamics). Many difficulties plague empirical studies; in particular, most MPAs are too small to affect fisheries in ways that are detectable at the fisheries management scale (Russ 2002). Hence, empirical studies are generally restricted to small scale effects on local fisheries. Modeling studies do not have such constraints, but rely on many assumptions and have been criticized as unrealistic and offering conflicting conclusions (e.g. Willis et al. 2003).

Empirical studies on the effects of MPAs on fisheries have shown that: (1) after protection over a range of years, catch per unit effort (CPUE) of many exploited species are often higher in the fished areas closest to MPA boundaries (e.g. Murawski et al. 2005, Abesamis et al. 2006a, Goñi et al. 2006, 2008) or have increased after MPA creation (e.g. McClanahan \& Mangi 2000, Russ et al. 2003, 2004, Stobart et al. 2009); (2) spatial redistribution of fishing effort around MPAs often results in effort concentration near MPA boundaries (e.g. McClanahan \& Kaunda-Arara 1996, McClanahan \& Mangi 2000, Kelly et al. 2002, Murawski et al. 2005, Goñi et al. 2008); (3) CPUE may be locally depleted when fishing effort concentrates near MPA boundaries (McClanahan \& Kaunda-Arara 1996, McClanahan \& Mangi 2000, Goñi et al. 2006, Stobart et al. 2009); (4) the spatial extent of detectable spillover effects is limited to a few hundred to a few thousand meters from MPA boundaries, depending on species mobility and habitat characteristics (e.g. Russ et al. 2004, Abesamis $\&$ Russ 2005, Murawski et al. 2005, Abesamis et al. 2006b, Goñi et al. 2006, Forcada et al. 2009), although this extent is strongly affected by fishing effort dynamics near boundaries and gear efficiency (McClanahan \& Mangi 2000, Goñi et al. 2008).

MPA benefits for fisheries are expected to result more from increased egg production and export of eggs and larvae than from spillover of adults (Jennings 2000, Russ 2002). However, because of the temporal variability of larval survival and settlement as well as the large area over which it is expected to occur, the recruitment effect is hard to detect. Thus, spillover is presently the only tangible index of potential fishery benefit of MPAs. However, despite all the available evidence, and because such studies are technically and logistically difficult (Russ 2002), no empirical study has yet quantified spillover or determined its contribution to local catches. A first step was made by Abesamis et al. (2006a), who estimated the potential maximum contribution of spillover from the Apo marine reserve (occupying $\sim 10 \%$ of the fishing area) at less than $10 \%$ of the overall yield of the Apo Island fisheries.

Knowledge of animal movements is key in developing spatial management tools such as MPAs, and has been studied to investigate spillover from MPAs to adjacent fisheries (e.g. Zeller et al. 2003, Goñi et al. 2006, Tupper 2007). However, to our knowledge, only Rowe (2001) for lobster Homarus gammarus and Tupper (2007) for surgeonfish Naso lituratus have demonstrated discernible net outward movement from an MPA. Nevertheless, Tupper found little outward movement for other exploited fishes studied, and concluded that spillover was species-specific and influenced by reef topography.

In this study, we investigated movement of the spiny lobster Palinurus elephas and spillover to the adjacent fishery from the Columbretes Islands Marine Reserve (CIMR; hereafter also called MPA). The CIMR was created in 1990, and the study initiated in 1997 showed that lobster abundance in the reserve was 5 to 20 times greater than in comparable fished areas (Goñi et al. 2001) and also demonstrated lobster spillover to the fishery (Goñi et al. 2006). In that study, individuals tagged inside the CIMR and recaptured in the surrounding fishery were used to track the CIMR origin of lobster harvested within $1500 \mathrm{~m}$ from the boundary. In the present study we used a decade (1997 to 2007) of tag-recapture data, and set out to: (1) estimate lobster emigration rates from the CIMR to the adjacent fished grounds, (2) quantify lobster spillover from the CIMR, (3) assess the spillover contribution to the commercial catch, and (4) compare spillover contribution with lost fishing grounds by the creation of the CIMR. We used a model developed by Hilborn (1990) to estimate movement rates based on tag-recapture data; spillover was quantified by combining estimates of emigration and of tagged lobster abundance in the MPA.

\section{MATERIALS AND METHODS}

The species. Palinurus elephas is a spiny lobster from temperate waters, widely distributed in the Northeast Atlantic and the Mediterranean. It inhabits rocky and coraligenous habitats from nearshore to depths of 200 m (Goñi \& Latrouite 2005). It is a long-lived (maximum estimated age of $20+\mathrm{yr}$ ), slow-growing species that matures at 3 to $4 \mathrm{yr}$ of age ( $80 \mathrm{~mm}$ carapace length [CL] in the Mediterranean) and reproduces once a year. The egg-bearing period extends from September to February (Goñi et al. 2003a). Tagging studies conducted in the Atlantic and Mediterranean (reviewed in Goñi \& Latrouite 2005) indicate that adult movement is restricted, with most individuals moving $<5 \mathrm{~km}$. Inshore-offshore migrations have been reported for both Atlantic and Mediterranean populations, and have been inferred in the CIMR from seasonal bathymetric changes in abundance (Goñi et al. 2001).

Study site and fishery. The study was carried out in the CIMR and surrounding fishing grounds (Fig. 1). 
Situated $50 \mathrm{~km}$ from the coast at the edge of the continental shelf, the CIMR protects $44 \mathrm{~km}^{2}$ of volcanic rock and coraligenous habitats (maërl beds), with patches of gravel, sand, and mud extending down to $80 \mathrm{~m}$ depth. Fishing grounds near the CIMR consist of areas with patches of rock and maërl over expanses of gravel, sand, and mud at depths of 50 to $90 \mathrm{~m}$. The CIMR harbors traditional fishing grounds of Palinurus elephas; legislation prohibits all commercial fisheries (including lobster fishing), and this regulation is well enforced. Commercially, P. elephas is the most important spiny lobster in the Mediterranean and North-eastern Atlantic. Northwestern Mediterranean fisheries are managed by a 6 mo closed season during the egg bearing period (September to February), a minimum landing size of $90 \mathrm{~mm} \mathrm{CL}$, and the prohibition of landing ovigerous females. Excess fishing has depleted $P$. elephas populations and, although Mediterranean populations are considered overfished, they are still targeted by small artisanal boats in many areas,

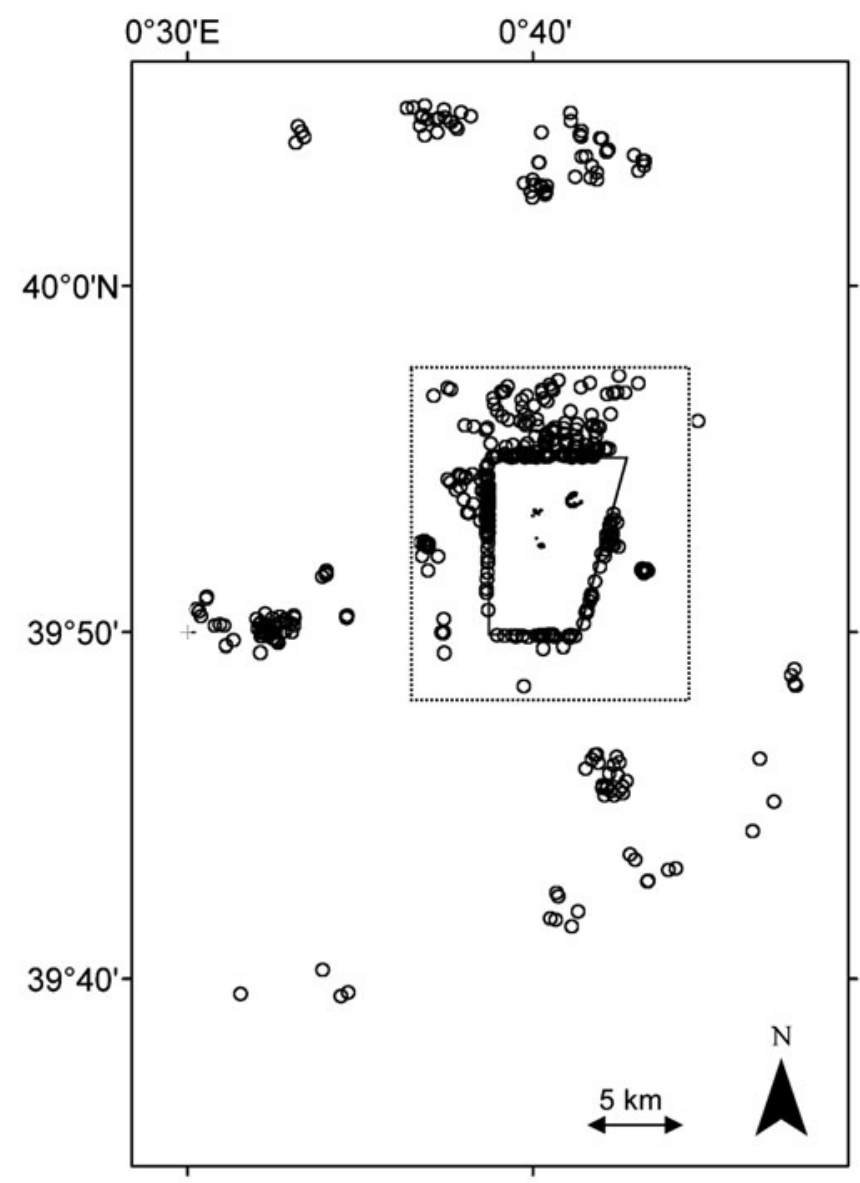

Fig. 1. Spatial distribution of commercial fishing effort in local ( $<5 \mathrm{~km}$ from boundary, dotted line) and regional fishing grounds during the study period (1997-2007). Internal solid lines: boundary of Columbretes Islands Marine Reserve (CMR). (O) fishing set especially around archipelagos and islands (Goñi \& Latrouite 2005). Due to the offshore location of the fishing grounds where the CIMR was implemented, few boats were prepared to venture to the area, and after its creation the number even declined (D. Kersting, pers. comm.). During the study period, 3 boats fished consistently through the season from 1997 to 2003, and only 2 boats operated in later years. Spatially, lobster fishing effort was distributed near the MPA $(<1 \mathrm{~km}$ from the boundary), in contiguous grounds up to $5 \mathrm{~km}$ from the MPA (1 to $5 \mathrm{~km}$ from the boundary), and in patchily distributed grounds farther away (10 to $30 \mathrm{~km}$ from the boundary) (Fig. 1). For the purpose of this study, we define 'regional fishing grounds' (or regional fishery) as the lobster grounds within $30 \mathrm{~km}$ of the CIMR boundary; 'local fishing grounds' (or local fishery) are defined as those within $5 \mathrm{~km}$ (Fig. 1). The extension of the regional lobster grounds (including those in the MPA) is around $189 \mathrm{~km}^{2}$; the extension of the local lobster fishing grounds (including those in the MPA) is around $107 \mathrm{~km}^{2}$. The area of traditional lobster grounds closed to fishing by the CIMR amounts to $\sim 34 \mathrm{~km}^{2}$ (18 and $32 \%$ of the available regional and local grounds, respectively).

Data collection. Tag-release and recapture program: We conducted annual experimental fishing surveys inside the CIMR from 1997 to 2006 following a random sampling design over lobster habitats (Goñi et al. 2003b). All surveys were conducted during a 5 to $10 \mathrm{~d}$ period in June prior to reproduction (except in 1998 and 1999 when surveys were conducted in August and September), when the probability of capture of females and males should be similar (Goñi et al. 2003b). Fishing was done with the same type of fishing gear used in the local commercial fishery: wide mesh (160 mm stretched-mesh inner panel) trammel-nets of standard $(600 \mathrm{~m})$ length. This gear typically selects individuals over 70 to $80 \mathrm{~mm}$ CL. Fishing effort was of 18 fishing sets of standard length by survey, and remained constant during the study period.

Annually (except in 2003 when no tagging was conducted), all lobsters captured in the surveys were tagged with Hallprint T-bar tags inserted dorsolaterally between the first and second abdominal segments. Tagged lobsters were released inside the CIMR as close as possible to the capture location. Care was exercised during the catching and tagging process to minimize injuries. Injured lobsters were returned to the water without tagging. The tag number, CL (mm), and sex were all recorded for each lobster tagged, as well as the date and position of release. Tag and release of lobsters outside the CIMR was attempted in 1997 with little success: low catch rates in fished areas yielded very few lobsters for tagging. 
Lobsters tagged during 1997 to 2006 were recaptured inside the CIMR during subsequent experimental fishing surveys from 1998 to 2007. For each recapture, the tag number, $\mathrm{CL}$, and date and position of recapture were recorded. Recaptures outside the CIMR were obtained in the adjacent fishery during the 6 mo fishing season each year from 1998 to 2007. The small number of boats operating in the fishery allowed a good collaboration with the fishers and ensured a high rate of notification of the recaptures obtained outside the MPA; tags and information on lobster size, as well as date and position of capture were also supplied by fishers. A 12 Euro reward was advertised and given in return for every recapture reported. Time at liberty of recaptured lobsters ranged from 1 to $10 \mathrm{yr}$. Only first time recaptures and lobsters recaptured after $>1 \mathrm{yr}$ at liberty were considered in this study.

Commercial catch and effort data: Commercial catch and effort data from the fishery were collected from an onboard observer program (totaling 477 fishing sets) conducted from 1998 to 2007 (except 2004). Sampling was done for 1 to $5 \mathrm{wk}$ per season. To ensure that the fishing effort data were representative of the true spatial distribution in the fishery, observers sampled all fishing sets undertaken during the sampling week. The lobster catch (number, size, tagged/ untagged condition) and fishing location were recorded for each fishing set.

Lobster effort in the regional fishery by year was estimated as the product of the number of boats in the fishery, the mean number of fishing sets per days per boat, and the mean number of fishing day per year. We calculated the annual lobster catch from the local and regional fishing grounds as the product of the mean annual CPUE within each of these areas (from the observer data) and the mean annual fishing effort deployed in each area.

Estimation of movement. Lobster movement from the CIMR to the adjacent fishing grounds was investigated using the model developed by Hilborn (1990). We considered 2 areas in the model: Area 1 was the CIMR; Area 2 was the regional fishing grounds. All lobsters tagged were caught and released in Area 1. Because no lobsters were tagged outside the MPA, it was not possible to estimate movement rates from outside to inside the MPA; thus, for tagged individuals, the estimated movement rate represents net emigration. The model follows the number of tagged and released individuals. We treated tags released in a year as a cohort of individuals and tracked the abundance of thjis cohort by area and time. Movement rates of males and females were expected to be different, so we considered them as separate groups of tags. The model is based on the following equations:

$$
\begin{aligned}
& N_{j, g, a, t}=G_{j, g} \text { if } \mathrm{t} \text { is } T_{j, g} \\
& N_{j, g, a, t+1}=\sum_{i} N_{j, g, a, t} S_{j, a, t} m_{j, a, t} \text { if } t+1 \text { is not the time } \\
& \text { of release for group } g \\
& s_{j, a, t}=s_{\text {natural }, j} s_{\text {shed }, j}\left(1-u_{j, a, t}\right) \\
& \hat{R}_{j, g, a, t}=N_{j, g, a, t} u_{j, a, t} r_{j, 2} \text { if area } a \text { is outside reserve } \\
& \hat{R}_{j, g, a, t}=N_{j, g, a, t} e_{j, 1, t} \quad \text { if area } a \text { is inside reserve }
\end{aligned}
$$

where the data are the tags released and recovered and:

$T_{j, g} \quad$ is the time period tagged lobsters of sex $j$ in group $g$ were released

$G_{j, g, t}$ is the number of tagged lobsters released of sex $j$ and group $g$ at time $t$

$R_{j, g, a, t}$ is the observed number of tagged lobsters returned of sex $j$ and group $g$, in area $a$, at time $t$

$R_{j, a, t} \quad$ is the observed number of tagged lobsters returned of sex $j$ for all groups, in area $a$, at time $t$

We estimated the following parameters or model outputs:

$N_{j, g, a, t}$ is the predicted number of tagged lobsters alive of sex $j$ from group $g$, in area $a$, at time $t$

$u_{j, a, t}$ is the exploitation rate for tagged lobsters of sex $j$ in area $a$, at time $t$. This is assumed to be 0 inside the MPA

$m_{j, 1,2, t}$ is the movement rate of lobsters sex $j$ from Area 1 to Area 2, at time $t$

$s_{j, a, t} \quad$ is the survival of tagged lobsters of sex $j$ from natural and fishing mortality and losses due to tag shedding in area $a$ at time $t$

$S_{\text {natural }, j}$ is the survival of lobster of sex $j$ from natural mortality

$S_{\text {shed }, j}$ is the tag retention rate (1-tag shedding) of lobster of $\operatorname{sex} j$

$r_{j, 2} \quad$ is the proportion of tags of lobsters of sex $j$ returned when captured in Area 2 (outside the MPA)

$\mathrm{e}_{j, 1, t} \quad$ is the proportion of lobsters of sex $j$ sampled in Area 1 (inside the MPA) at time $t$

$\hat{R}_{j, g, a, t}$ is the predicted number of tags of lobsters of sex $j$ and group $g$ returned when captured in Area 2 (outside the reserve) at time $t$

In the model, losses of tagged lobster from natural mortality and from tag shedding cannot be distinguished. Thus, to calculate natural mortality we used an annual probability of tag shedding of 4.1 and $7.5 \%$ for female and male Palinurus elephas, respectively (González-Vicente et al. 2009).

We made the usual assumptions of tagging analyses: (1) all tags are recognized, (2) survival from natural mortality and tag shedding are the same in all areas, (3) tagged and untagged individuals have the same probability of movement.

We made the following additional assumptions guided by our empirical observations: 
(4) Movement from outside to inside the MPA is close to zero and can be ignored. To estimate movement between areas one normally needs to tag individuals in all areas. In this case tagging outside the MPA was not feasible, but we know that exploitation rates outside of the CIMR are very high relative to movement rates. Thus, we do not expect individuals to be able to move inside the MPA during the fishing season or to survive in sufficient numbers to make appreciable immigration during the closure period.

(5) Exploitation rate is proportional to the effort observed within $5 \mathrm{~km}$ of the CIMR boundary. Most of the recaptures occurred within $5 \mathrm{~km}$ from the MPA, and we made the mean exploitation rate $u$ vary by year as a function of the percentage (\%) of the annual observer effort deployed within this area relative to Area 2.

(6) Movement rates are the same for all years in the study except for 2001. The data suggest that an unusually large portion of the individuals moved outside of the MPA in 2001.

For each combination of group, sex, area and time, we had observed $R_{j, g, a, t}$ and predicted $\hat{R}_{j, g, a, t}$ recoveries. We assumed that the recoveries would be Poisson distributed so the likelihood for the tag analysis is

$$
L\left\{R_{j, g, a, t} \mid \hat{R}_{j, g, a, t}\right\}=\prod \prod_{j} \prod_{a} \prod_{t} \frac{\mathrm{e}^{-\hat{R}_{j, g, a, t} \hat{R}_{j, g, a, t} R_{j, g, a, t}}}{R_{j, g, a, t} !}
$$

where $\Pi$ is the product of all the individual likelihoods for each sex, tag group, area and time period.

Estimation of lobster abundance inside the reserve. For any given year $t$, population abundance of lobster of sex $j$ in the CIMR $\left(P_{j, t}\right)$ was estimated as:

$$
P_{j, t}=C_{j, t} /\left(R_{j, t} / N_{j, 1, t}\right)
$$

where $C_{j, t}$ is the number of lobster of sex $j$ caught (tagged+untagged) in the CIMR during the experimental fishing survey in year $t, R_{j, t}$ is the number of tags recaptured of sex $j$ in the survey in year $t$, and $N_{j, 1, t}$ is the total number of tagged lobster of sex $j$ available in the CIMR at the beginning of year $t$ as estimated by the tagged population model (Eq. 1).

Estimation of spillover. We estimated mean annual spillover $(S j)$ of lobster sex $j$, or the mean number of lobster sex $j$ emigrating per year from the MPA (Area 1) to the fished area (Area 2), as:

$$
S_{j}=P_{j} \times M_{j, 1,2}
$$

Where $P_{j}$ is the mean abundance of lobster of sex $j$ (tagged + untagged) in the CIMR over the study period and $M_{j, 1,2}$ is the mean annual sex-specific probability of movement from the MPA (emigration rate) derived from the tagged population model for the period 1997 to 2006 (except in 2001 which was $M_{j, 1,2,2001)}$.

\section{RESULTS}

\section{Tag-recapture}

A total of 5334 lobsters (53.3\% female) were caught, single-tagged and released in the CIMR during 1997 to 2006. Of these, 566 (52.3\% female) were recaptured inside the MPA during the 1998 to 2007 surveys and 729 (44.7\% female) were recaptured during the same period in the fished area near the MPA. Thus, the sex ratio of both the newly tagged lobster and the recaptures in the MPA was slightly higher for females, while recaptures in the surrounding fishery were higher for males.

The percentage of lobsters recaptured annually inside the MPA from the number of all those released was $2.3 \%$ for males and $1.8 \%$ for females, with oscillations around these mean values over the study period. In the fishery, recapture rates were higher for males $(3.4 \%)$ and similar for females $(1.9 \%)$, exhibiting a marked peak in 2002 (Fig. 2).

During 1997 to 2006, the mean CL of newly tagged lobsters (inside the MPA) increased from 100 to $111 \mathrm{~mm}$ among females and from 109 to $132 \mathrm{~mm}$ among males. At the beginning of the study, the mean size of lobster recaptured inside and outside the CIMR was similar but later became larger inside the CIMR than in the adjoining areas (Fig. 3), suggesting that large lobsters migrated comparatively less than small and medium ones.

\section{Commercial effort and catch}

At the regional level, estimated lobster fishing effort remained approximately constant at around 1500 to 1900 fishing sets $\mathrm{yr}^{-1}$ (mean: 1628 fishing sets $\mathrm{yr}^{-1}$ ) during the study period (except in 2005 when fishing effort was lower: Fig. 4). Effort levels remained relatively stable, even when the number of vessels that targeted lobster declined (from 3 during 1998-2003 to 2 thereafter) because fishing effort per boat increased (from

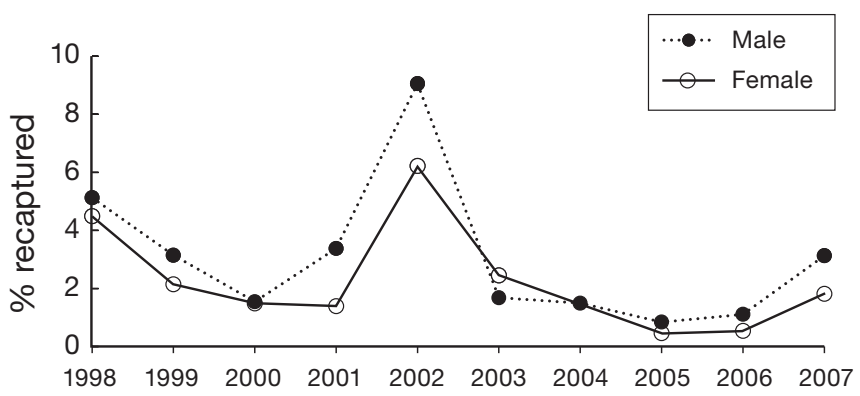

Fig. 2. Palinurus elephas. Annual recapture rates of tagged lobsters in the fishery adjacent to the CIMR (\%) 

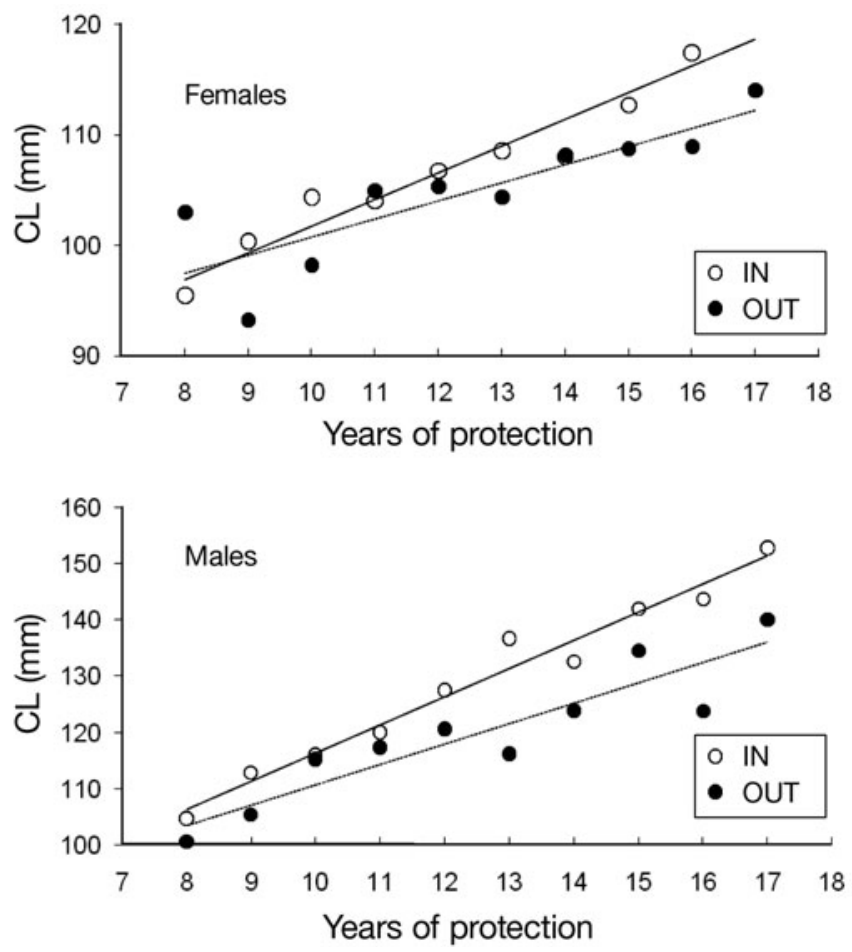

Fig. 3. Palinurus elephas. Mean carapace length (CL) of recaptured female (upper panel) and male (lower panel) lobsters in the CIMR (IN) and in the adjacent fishery (OUT) during the study period ( 7 to $17 \mathrm{yr}$ after the reserve was established)

5.8 sets $\mathrm{d}^{-1}$ during $1998-2005$ to 8.5 thereafter). The number of commercial sets sampled (17 to $99 \mathrm{yr}^{-1}$ ) corresponded to 1 to $6 \%$ of the estimated annual regional effort. A large portion of sets (45\%) occurred $<1 \mathrm{~km}$ from the CIMR boundary, $25 \%$ in grounds from 1 to $5 \mathrm{~km}$, and $30 \%$ at greater distance. The spatial distribution of effort varied over time in relation to the CIMR, concentrating towards the boundary during 2000 to 2003 and declining thereafter (Fig. 5).

The estimated mean annual catch for sexes combined was $11461 \pm 5039$ SD lobster $(6016 \pm 2808 \mathrm{SD}$ kg) in the regional fishery, of which $8592 \pm 5517$ SD lobster $(3927 \pm 3292 \mathrm{SD} \mathrm{kg})$ corresponded to the local fishery.

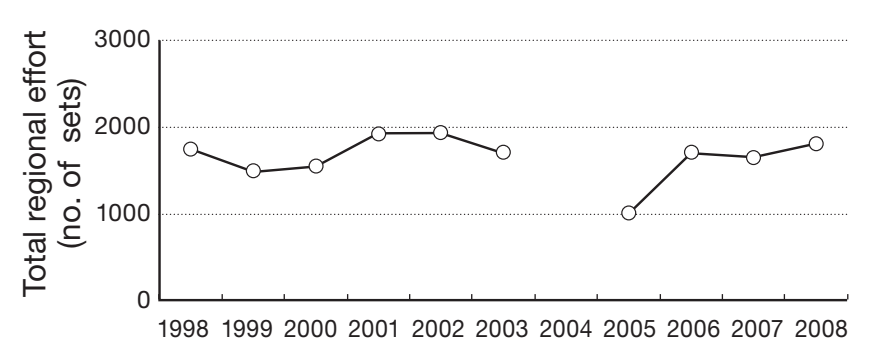

Fig. 4. Estimated total annual effort in number of fishing sets deployed in the regional lobster fishery around the CIMR during the study period. No data available for 2004

\section{Model estimates: mortality, exploitation and movement rates}

Natural mortality of Palinurus elephas in the CIMR was $16 \% \mathrm{yr}^{-1}$ for females and $20 \% \mathrm{yr}^{-1}$ for males (Table 1). The estimated exploitation rate in the adjacent fishery was very high, indicating that virtually all males emigrating from the MPA and $\sim 80 \%$ of the females were harvested within the following season (Table 1). The model estimated that sampling rates inside the MPA were higher among males and that all tags recaptured outside the MPA were reported. This reporting rate is consistent with high mean reporting rates $(1.11 \pm 1.19 \mathrm{SD})$ estimated from the observer program over the study period. Estimates indicated that on average $3.7 \%$ of the females and $6.7 \%$ of males in the CIMR were likely to emigrate annually from the MPA. These rates were 3 to 4 times higher in 2001 (Table 1), as expected given the high proportion of recaptures in 2002 (Fig. 2).

\section{Lobster abundance inside the reserve}

Adult lobster abundance in the CIMR at the end of the study period ( 22000 females and 5000 males) was lower than in the earlier years and was consistently higher among females (Fig. 6). Male abundance was stable and higher from 1998 to 2002 than from 2003 to 2007; female levels were more variable among years. Mean adult abundance (sexes combined) in the CIMR during 1997 to 2006 was 31144 lobsters \pm 11448 SD (range: 18316 to 44 179) (Table 2).

\section{Spillover contribution to the fishery}

Mean spillover was 2065 lobsters $\mathrm{yr}^{-1}( \pm 2124$ SD), which amounted to $6.6 \%$ of the mean annual population in the CIMR. Mean anual spillover in weight was $2069 \mathrm{~kg} \mathrm{yr}^{-1}( \pm 2167 \mathrm{SD})$. Applying the exploitation rate

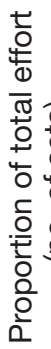

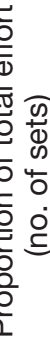

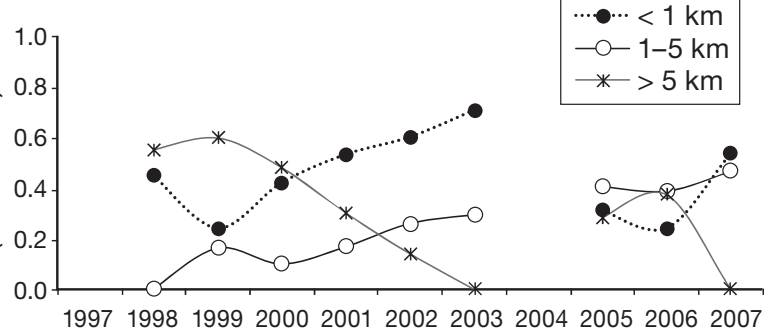

Fig. 5. Fraction of the total annual fishing effort (\% no. of sets) in the lobster fishery in areas located at different distances of the CIMR during the study period. No data available for 2004 
Table 1. Palinurus elephas. Model parameter estimates (means and 95\% confidence intervals) for females and males (1997-2006)

\begin{tabular}{|c|c|c|c|c|}
\hline \multirow[t]{2}{*}{ Parameters } & \multicolumn{2}{|c|}{ Females } & \multicolumn{2}{|c|}{ Males } \\
\hline & Mean & $\pm \mathrm{CI}$ & Mean & $\pm \mathrm{CI}$ \\
\hline Natural mortality $\left(1-S_{\text {natural }}\right)$ & 0.163 & $0.132-0.193$ & 0.199 & $0.171-0.226$ \\
\hline Exploitation rate in fishing grounds (Area 2) $(u)$ & 0.783 & $0.605-0.976$ & 1.000 & $0.913-1.000$ \\
\hline $\begin{array}{l}\text { Proportion of tags that are returned when captured in the fishery } \\
\text { outside the reserve }(r)\end{array}$ & 1.000 & $0.491-1.000$ & 1.000 & $0.501-1.000$ \\
\hline Sampling rate for all lobsters inside the reserve $(e)$ & 0.045 & $0.038-0.054$ & 0.067 & $0.057-0.078$ \\
\hline Movement rate from the reserve (Area 1 to 2$)$ excluding $2001\left(m_{1,2}\right)$ & 0.037 & $0.031-0.046$ & 0.067 & $0.057-0.079$ \\
\hline Movement rate from the reserve (Area 1 to 2$)$ in $2001\left(m_{1,2,2001}\right)$ & 0.152 & $0.106-0.211$ & 0.240 & $0.193-0.292$ \\
\hline
\end{tabular}

Table 2. Palinurus elephas. Mean $( \pm$ SD) estimates of population abundance in the CIMR (1997-2006) derived from model estimates of the tagged population size and emigration probabilities $\left(\% \mathrm{yr}^{-1}\right)$, spillover (no. lobster $\mathrm{yr}^{-1}$, wt $\left.\mathrm{yr}^{-1}\right)$ and harvested spillover (no. lobster $\mathrm{yr}^{-1}$, wt $\mathrm{yr}^{-1}$ )

\begin{tabular}{|c|c|c|c|c|c|}
\hline & \multirow{2}{*}{$\begin{array}{c}\text { Abundance in reserve } \\
\mathrm{N} \text { lobster }\end{array}$} & \multicolumn{2}{|c|}{ Spillover } & \multicolumn{2}{|c|}{ Harvested spillover } \\
\hline & & $\mathrm{N}$ lobs $\mathrm{yr}^{-1}$ & kg lobs $\mathrm{yr}^{-1}$ & $\mathrm{~N}$ lobs $\mathrm{yr}^{-1}$ & $\mathrm{~kg}$ lobs $\mathrm{yr}^{-1}$ \\
\hline Females & $20645 \pm 7328$ & $1094 \pm 1175$ & $956 \pm 1073$ & $857 \pm 920$ & $749 \pm 840$ \\
\hline Males & $10498 \pm 4119$ & $971 \pm 996$ & $1113 \pm 1123$ & $971 \pm 996$ & $1113 \pm 1123$ \\
\hline Total & $31143 \pm 11448$ & $2065 \pm 2124$ & $2069 \pm 2167$ & $1828 \pm 1890$ & $1861 \pm 1938$ \\
\hline
\end{tabular}

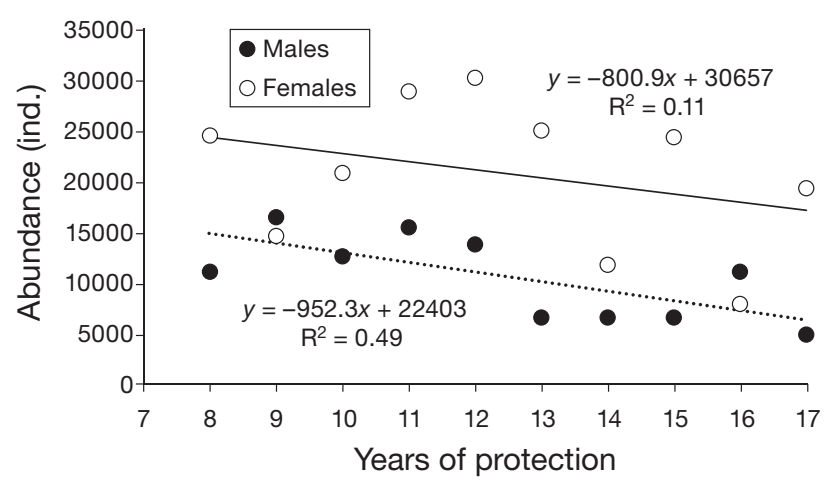

Fig. 6. Palinurus elephas. Estimates of lobster abundance (no.) in the CIMR by sex as a function of years of protection. Year 1 corresponds to 1991 when enforcement was effectively in place

of males and females in the fishery, harvested spillover amounted to 1828 lobsters $\mathrm{yr}^{-1}( \pm 1890 \mathrm{SD})$ or $1861 \mathrm{~kg} \mathrm{yr}^{-1}$ ( \pm 1938 SD: Table 2). This harvested spillover represented 16 and $21 \%$ of the annual catches by number of the regional and local fisheries, respectively. Because the mean size of the tagged lobsters recaptured in the fishery was on average $33 \%$ larger than those untagged (females: $26 \%$; males: $40 \%$ :
R. Goñi, D. Díaz \& S. Mallol unpubl. data) spillover in weight represented 31 and $43 \%$ of the corresponding annual catches.

Taking into consideration the loss of $18 \%$ of the regional fishery grounds and $32 \%$ of the local fishing grounds by the establishment of the CIMR, and assuming similar productivity of the grounds inside and outside, we estimate that there has been a mean net loss to the fishery in terms of the number of lobster caught of 2 and $11 \%$ in the regional and local fisheries, respectively. In terms of catch in weight, however, we estimate a net gain of $>10 \%$ (Table 3 ). Excluding the extraordinary spillover event of 2001 and subsequent high catch of 2002, the mean harvested spillover contribution to the catch would have represented 23 and $35 \%$ of the regional and local catch in weight respectively and would have yielded a net gain of 3 to $5 \%$ of the annual catch by weight.

Table 3. Palinurus elephas. Gross and net changes in lobster harvest in the regional and local $P$. elephas fisheries after establishment of the CIMR. Mean over 8 to 17 yr protection period

\begin{tabular}{|lccccc|}
\hline Fishery & $\begin{array}{c}\text { Loss of fishery } \\
\text { area by establishment } \\
\text { of CIMR (\%) }\end{array}$ & $\begin{array}{c}\text { Annual gain through } \\
\text { harvested spillover } \\
\text { \% of total catch } \\
\text { (No.) }\end{array}$ & $\begin{array}{c}\text { Net change } \\
\text { in catch } \%\end{array}$ \\
\hline $\begin{array}{l}\text { Regional } \\
\text { Local }\end{array}$ & 18 & 15.9 & 30.9 & $($ No.) & $(\mathrm{kg})$ \\
\hline
\end{tabular}




\section{DISCUSSION}

For the first time, this study quantifies the speciesspecific spillover from an MPA and its net contribution to local fishery catches. Approximately $7 \%$ of the Palinurus elephas protected in the CIMR, immigrated annually to the adjacent fished grounds, such that their spillover contribution to the annual commercial catch by weight was 31 to $43 \%$. This provided a mean net gain of $>10 \%$ by weight of the adjacent fishery catch. Although the number of lobsters spilling over annually did not quite make up for the loss of fishing grounds set aside in the CIMR, it did in weight because the mean size of the lobsters emigrating from the MPA were larger than those outside. Our study benefited from a unique data set made up of $10 \mathrm{yr}$ of tag-recapture data in the MPA and of recaptures in the fished area. Also extraordinary was the fishers' collaboration that resulted in high tag reporting rates, made possible by the small number of fishing boats involved in the fishery. This study contributes in filling a gap in the empirical knowledge of fishery effects from MPAs, as it estimates spillover and its contribution to catches, while prior studies had only provided evidence of spillover, mostly in the form of higher catch rates or yields adjacent to MPA boundaries (e.g. see Russ et al. 2004, Goñi et al. 2006, 2008 and references therein).

Virtually all migrants leaving the MPA were harvested by the end of the following season and $95 \%$ of them were caught within $1 \mathrm{~km}$ from the CIMR boundary. High exploitation rates characterize many spiny lobster fisheries, where few lobster in the legal size classes escape the fishery every year (e.g. Rowe 2001, Iacchei et al. 2005); fishing the line along MPA boundaries exacerbates exploitation and may produce local depletion (e.g. McClanahan \& Mangi 2000, Stobart et al. 2009). In our study, exploitation was intensified along the CIMR boundary by effort concentration at $<1 \mathrm{~km}$, reaching up to $60-70 \%$ of the total regional effort during 2002 to 2003 (Fig. 5).

The emigration rate of male Palinurus elephas was almost double that of females. This was consistent with previous reports of greater mobility of males for several species of spiny lobsters (e.g. MacDiarmid \& Butler 1999, Frisch 2007), including P. elephas (Follesa et al. 2009). Higher recapture rates observed in this study suggest that male $P$. elephas exhibit a similar behavior in the CIMR, although assessing the full extent of movement behavior is hindered by concentration of effort around the CIMR that prevents lobster moving far from the boundary before being captured.

The benefits of spillover from the CIMR to the local fisheries depend on the mechanism of spillover and the dynamics of the fishery. Several mechanisms may facilitate spillover inter alia: (1) nomadic or home range movements near MPA boundaries, (2) seasonal migrations, or migrations forced by extraordinary events; and (3) density-dependent movements. Moderate movements of Palinurus elephas (relative to the size of the CIMR), continuity of habitats through a large part of its perimeter and high exploitation rates that intercept migrants, mean that the protected population is exposed to fishing mortality. Thus, movements near the boundaries exposing lobsters to harvestwhich are not balanced in the other direction because of lower lobster abundance outside the MPA - may have negative effects on their abundance that extend well into the MPA. This phenomenon, called 'dispersion imbalance' by Walters et al. (2007) is clearly consistent with our observations of high exploitation rates in the adjacent fishery and of declining abundance in the CIMR.

Seasonal inshore-offshore migrations could also facilitate spillover of Palinurus elephas from the CIMR. These migrations have been documented in Atlantic and Mediterranean populations of $P$. elephas (Goñi \& Latrouite 2005) and inferred in the CIMR from seasonal bathymetric changes in abundance (Goñi et al. 2001). Seasonal feeding or reproductive migrations of lobster species have been proposed to explain density changes in marine reserves and declines due to edge fishery harvesting of migrants (e.g. MacDiarmid \& Breen 1992).

Greater spillover and emigration rates in 2001 (3 to 4 times higher than average) could have been caused by movement to greater depths (beyond the CIMR boundaries) to lessen the effects of extreme weather conditions caused by a decadal storm that hit the northwestern Mediterranean in November 2001 (J. Pascual \& J. Font unpubl. data). The CIMR has a central line of small islands and shoals that convey wind energy downwards. We conjecture that during the storm, energy levels at the bottom were greater along the central line of islands than near the boundaries or outside the CIMR, and that in search of lower energy substrates, some lobsters may have found refuge in deep waters of the CIMR, while others may have spilled over the boundary. Support for this comes from the exceptionally high commercial catches near the MPA during the 2002 fishing season, known through declarations from fishers documented by the local press; this is consistent with a peak in fishing effort along the CIMR boundaries observed in that period (Fig. 5). Massive migrations of lobsters in response to unfavorable meteorological events have been documented in shallow water species (e.g. Panulirus argus, Herrnkind 1980). In our study, a storm occurred during the winter forcing lobsters to move out of the MPA while the fishery was closed. Higher yields during the following fishery season suggest that lobsters had not returned to their original territories, either having relocated within the 
fishing grounds or having been intercepted on their way back to shallower water. Design of MPAs requires careful spatial considerations for species which have similar bathymetric responses and which are located in areas where meteorological events could force their relocation; otherwise the beneficial roles of MPAs may be jeopardized.

Spillover from the CIMR may also be driven by density-dependent emigration, mainly among males. Emigrants were mostly medium or small lobster, while the largest individuals tended to remain in the MPA (Fig. 3). Competitive exclusion has been shown to exclude subordinate fish through interference competition in old Kenyan (McClanahan et al. 2007) and Philippine MPAs (Abesamis \& Russ 2005), indicating processes of selection for fewer but larger individuals. We propose that a density-dependent process may be limiting lobster abundance in the CIMR, where the carrying capacity would be defined by the number and territorial behavior of large males. Group denning is common in Palinurids, including Palinurus elephas (Mercer 1973). Den sharing often results in the formation of size-based dominance hierarchies (Atema \& Cobb 1980), where social groups may be rigid with respect to sex structure: e.g. in $P$. versicolor 2 males never occupy the same den simultaneously (Frisch 2008). Furthermore, female palinurids mate once per reproductive period whilst males (large males in particular) are capable of fertilizing several females (MacDiarmid \& Butler 1999). If the sex ratio of a population is balanced, females are likely to be in high demand, since males can mate with more females than are available (Frisch 2008). Under these circumstances, sociobiological theory predicts the formation of polygynous groups (harems) in which dominant (usually large) males defend females or critical resources such as dens (Atema \& Cobb 1980). Therefore, the observed greater emigration rate of males and higher mean abundance of females in the CIMR are consistent with theory and expected when lobster abundance and size increase in a protected area.

We lack data on the evolution of lobsters in the CIMR during the early years of the MPA to fully understand the response of the lobster population to protection. However, it seems plausible that Palinurus elephas density responded swiftly to protection given their overfished status and moderate mobility relative to the size of the CIMR (Goñi et al. 2001). It is also likely that abundance and individual size grew gradually to a point in which dispersion imbalance and/or competition processes kicked in. At the time of MPA creation, it is conceivable that fishing effort relocated homogeneously around available grounds or in preferred areas outside the CIMR, only to coalesce gradually towards its boundaries as lobster abundance in the MPA grew, expanding and contracting thereafter as a function of fishing success on the MPA edge. A similar process was documented for the lobster Jasus edwardsii in an MPA in New Zealand (MacDiarmid \& Breen 1992). Lobster density increased with time of protection, but male density started to decline after 12 to 14 years as a result of seasonal migrations that exposed them to exploitation near the seaward boundary. The role of edge effects on benefits from MPAs have received limited attention, but effort concentration along MPA edges is increasingly recognized as a factor affecting MPA effectiveness (e.g. in small MPAs: Walters 2000, Walters et al. 2007) or modulating population responses to protection (e.g. Walters 2000, Barrett et al. 2007, Pande et al. 2008).

Our study of spillover from the CIMR suffers from some limitations and relies on several assumptions. (1) As detailed in the above paragraph, the absence of data prior to 1998 limits investigation of the spillover process. (2) Lack of tagging outside the MPA prevented estimation of immigration rates that were assumed negligible; therefore our estimate of spillover benefits must be considered a maximum. Nonetheless, this assumption was also made by other authors when studying spiny lobster fisheries around MPAs (Acosta 2002, McGarvey 2004), and it is supported by very high exploitation rates (78.3 and $100 \%$ in our study for females and males, respectively) and local depletion in the CIMR border fishery. We nevertheless attempted tagging lobsters outside the CIMR in 1997, but low catch rates in fished areas yielded insufficient lobsters and made experiments unfeasible; in retrospect, the large number of tagged individuals required to recapture individuals inside the MPA to estimate immigration would have been disproportionate, given the sampling effort allowed within the MPA, the high exploitation rates in the fishery and the low expected immigration rate values. (3) The estimate of the contribution of spillover to the catch is affected by the spatial distribution of effort in relation to the CIMR, which was calculated from observer data that had with lower coverage after 2002. (4) To determine if spillover offset losses from reduced fishing grounds, we assumed that lobster productivity was similar inside and outside the CIMR. Comparable juvenile abundance in both areas (R. Goñi, D. Díaz, S. Mallol unpubl. data) suggests that this is the case.

We conclude that lobster spillover from the CIMR during the period of 8 to 17 years of protection offset the loss of fishing grounds closed in the MPA and produced gains of $>10 \%$ in mean annual yields. MPAs are of great contemporary interest as fisheries management tools but major concerns remain, in particular the loss of fishing grounds and yields (Jones 2008). Our results show that adult spillover provided net benefits 
to the local fishery under the conditions of this study (i.e. highly exploited species with moderate movements and continuity of habitats across boundaries), and that these benefits were derived primarily from the fact that the lobsters were allowed to grow larger in the MPA before they emigrated. Other benefits of protection, e.g. from increased reproductive potential and recruitment, remain to be quantified. As yet however, adult spillover is the only quantifiable benefit of MPAs to fisheries and it is important to understand what the necessary conditions are for this gain to materialize. An obvious insight from this study is that MPAs and fished areas must form continuous systems with permeable boundaries for spillover to occur. Prolongation of the current study and a recent $20 \%$ expansion of the CIMR into adjacent lobster grounds may, in a few years, provide further illustration of the tradeoffs between biomass recovery, MPA size, and permeability. In a recent study of Jasus edwardsii, Freeman et al. (2009) showed that lobsters became increasingly likely to migrate from an MPA into adjacent fished areas as the proportion of protected reef and thus lobster density in each reef correlated positively with the proportion of the reef that was protected. Expansion of the CIMR would increase the proportion of contiguous lobster habitat closed to fishing and predictably lead to reduced spillover. Understanding the complex interplay between abundance and demography, habitat and permeability, and effort dynamics and spillover is a top priority of our future research efforts. Conclusions drawn from this study and its methodology, although from a small scale fishery, are valid for evaluating MPA fishery benefits and in understanding processes involved in similar and larger fishery-MPA systems.

Acknowledgements. We thank the skippers and crews of the 'Calypso', 'Catalá' and 'Nuevo Jose María' for their invaluable collaboration, and also thank O. Reñones and A. Quetglas for their significant contribution to the design of the study and data collection in the early years of the project. C. Gonzalez was responsible for database design and data processing, and M. C. Iglesias provided editorial help. We acknowledge the helpful comments of A. MacDiarmid, A. Parma, F. Alvarez and B. Stobart, and also those of 5 referees. This work was supported by the Spanish Secretaría General del Mar by grants to the Instituto Español de Oceanografía for the LANGOSTA and ERICOL projects.

\section{LITERATURE CITED}

Abesamis RA, Russ GR (2005) Density-dependent spillover from a marine reserve: long-term evidence. Ecol Appl 15: 1798-1812

Abesamis RA, Alcala AC, Russ GR (2006a) How much does the fishery at Apo Island benefit from spillover of adult fish from the adjacent marine reserve? Fish Bull 104(3): $360-375$
Abesamis RA, Russ GR, Alcala AC (2006b) Gradients of abundance of fish across no take-take marine reserve boundaries: evidence from Philippine coral reefs. Aquatic Conserv: Mar Freshw Ecosyst 16:349-371

Acosta CA (2002) Spatially explicit dispersal dynamics and equilibrium population sizes in marine harvest refuges. ICES J Mar Sci 59:458-468

Atema J, Cobb JS (1980) Social behavior. In: Cobb JS, Philips BF (eds) The biology and management of lobsters. Academic Press, New York, p 215-276

> Barrett NS, Edgar GJ, Buxton CB, Haddon M (2007) Changes in fish assemblages following 10 years of protection in Tasmanian marine protected areas. J Exp Mar Biol Ecol 345:141-157

Claudet J, Osenberg C, Domenici P, Badalamenti F and others (2010) Marine reserves: fish life history and ecological traits matter. Ecol Appl (in press)

Follesa MC, Cuccu D, Cannas R, Sabatini A, Deiana AM, Cau A (2009) Movement patterns of the spiny lobster Palinurus elephas (Fabricius, 1787) from a central eastern Mediterranean protected area. Sci Mar 73:499-506

Forcada A, Valle C, Bonhomme P, Criquet G, Cadiou G, Lenfant P, Sánchez-Lizaso JL (2009) Effects of habitat on spillover from marine protected areas to artisanal fisheries. Mar Ecol Prog Ser 379:197-211

Freeman DJ, MacDiarmid AB, Taylor RB (2009) Habitat patches that cross marine reserve boundaries: consequences for the lobster Jasus edwardsii. Mar Ecol Prog Ser 388:159-167

Frisch AJ (2007) Short- and long-term movements of painted lobster (Panulirus versicolor) on a coral reef at Northwest Island, Australia. Coral Reefs 26:311-317

Frisch AJ (2008) Social organization and den utilization of painted spiny lobster (Palinurus versicolor) on a coral reef at Northwest, Australia. Mar Freshw Res 59:521-528

Goñi R, Latrouite D (2005) Review of the biology, ecology and fisheries of Palinurus species of European waters: Palinurus elephas (Fabricius, 1787) and Palinurus mauritanicus (Gruvel, 1911). Cah Biol Mar 46:127-142

Goñi R, Reñones O, Quetglas A (2001) Dynamics of a protected Western Mediterranean population of the European spiny lobster Palinurus elephas (Fabricius, 1787) assessed by trap surveys. Mar Freshw Res 52:1577-1587

Goñi R, Quetglas A, Reñones O (2003a) Size at maturity, fecundity and reproductive potential of a protected population of the spiny lobster Palinurus elephas (Fabricius, 1787) from the Western Mediterranean. Mar Biol 143: 583-592

Goñi R, Quetglas A, Reñones O (2003b) Differential catchability of male and female European spiny lobster Palinurus elephas (Fabricius, 1787) in traps and trammel nets. Fish Res 65:295-307

> Goñi R, Quetglas A, Reñones O (2006) Spillover of lobster Palinurus elephas from a Western Mediterranean marine reserve. Mar Ecol Prog Ser 308:207-219

> Goñi R, Adlerstein S, Alvarez-Berastegui D, Forcada A and others (2008) Spillover from six western Mediterranean marine protected areas: evidence from artisanal fisheries. Mar Ecol Prog Ser 366:159-174

González-Vicente L, Díaz D, Mallol S, Goñi R (2009) Double tagging experiments and tag loss in Palinurus elephas. The Lobster Newsl 22:6-9

Herrnkind WF (1980) Spiny lobsters: patterns of movement. In: Cobb JS, Phillips DF (eds) The biology \& management of lobsters: physiology \& behaviour. Academic Press, New York, p 349-407

Hilborn R (1990) Determination of fish movement patterns 
from tag recoveries using maximum likelihood estimators. Can J Fish Aquat Sci 47:635-643

Hilborn R (2006) Faith-based. Fish Fish 31:554-555

Hilborn R, Stokes K, Maguire JJ, Smith T and others (2004) When can marine reserves improve fisheries management? Ocean Coast Manag 47:197-205

Iacchei M, Robinson P, Miller KA (2005) Direct impacts of commercial and recreational fishing on spiny lobster, Panulirus interruptus, populations at Santa Catalina Island, California, United States. Mar Freshw Res 39:1201-1214

Jennings S (2000) Patterns and prediction of population recovery in marine reserves. Rev Fish Biol Fish 10:209-231

Jones PJS (2008) Fishing industry and related perspectives on the issues raised by no-take marine protected area proposals. Mar Policy 32:749-758

Kelly S, Scott D, MacDiarmid AB (2002) The value of a spillover fishery for spiny lobsters around a marine reserve in New Zealand. Coast Manag 30:153-166

MacDiarmid AB, Breen PA (1992) Spiny lobster population change in a marine reserve. In: Proceedings of the Second International Temperate Reef Symposium, Batershill CN. et al. (ed) pp 47-56, 7-10 January 1992, Auckland, New Zealand NIWA Marine, Wellington, $252 \mathrm{p}$

MacDiarmid AB, Butler MJ IV (1999) Sperm economy and limitation in spiny lobsters. Behav Ecol Sociobiol 46:14-24

McClanahan TR, Kaunda-Arara B (1996) Fishery recovery in a coral-reef marine park and its effect on the adjacent fishery. Conserv Biol 10:1187-1199

McClanahan TR, Mangi S (2000) Spillover of exploitable fishes from a marine park and its effects on the adjacent fishery. Ecol Appl 10:1792-1805

McClanahan TR, Graham NAJ, Calnan JM, MacNeil MA (2007) Toward pristine biomass: reef fish recovery in coral reef marine protected areas in Kenya. Ecol Appl 17: 1055-1067

McGarvey R (2004) Estimating the emigration rate of fish stocks from marine sanctuaries using tag-recovery data. Fish Bull 102:464-472

Mercer JP (1973) Studies on the spiny lobsters (Crustacea: Decapoda: Palinuridae) of the West Coast of Ireland with particular reference to Palinurus elephas, Fabricius 1787. PhD Thesis, University College Galway

Murawski SA, Wigley SE, Fogarty MJ, Rago PJ, Mountain DG (2005) Effort distribution and catch patterns adjacent to temperate MPAs. ICES J Mar Sci 62:1150-1167

Editorial responsibility: Tim McClanahan, Mombasa, Kenya
Pande A, MacDiarmid AB, Smith PJ, Davidson RJ and others (2008) Marine reserves increase the abundance and size of blue cod and rock lobster. Mar Ecol Prog Ser 366: $147-158$

Polacheck T (1990) Year round closed areas as a management tool. Nat Resour Model 4:327-354

Rowe S (2001) Movements and harvesting mortality of American lobsters (Homarus americanus) tagged inside and outside no-take reserves in Bonavista Bay, Newfoundland. Can J Fish Aquat Sci 58:1336-1346

Russ GR (2002) Yet another review of marine reserves as reef fishery management tools. In: Coral Reef Fishes (ed. Sale P) Academic Press, San Diego, CA, p 421-443

> Russ GR, Alcala AC, Maypa AP (2003) Spillover from marine reserves: the case of Naso vlamingii at Apo Island, the Philippines. Mar Ecol Prog Ser 264:15-20

Russ GR, Alcalá AC, Maypa AP, Calumpong HP, White AT (2004) Marine reserve benefits local fisheries. Ecol Appl 14:597-606

Sánchez-Lizaso JL, Goñi R, Reñones O, García-Charton JA and others (2000) Density dependence in marine protected populations: a review. Environ Conserv 27:144-158

> Stobart B, Warwick R, González C, Mallol S, Díaz D, Reñones O, Goñi R (2009) Long term and spillover effects of a marine protected area on an exploited fish community. Mar Ecol Prog Ser 384:47-60

Tupper MH (2007) Spillover of commercially valuable reef fishes from marine protected areas in Guam, Micronesia. Fish Bull 105:527-537

Walters C (2000) Impacts of dispersal, ecological interactions and fishing effort dynamics on efficacy of marine protected areas: How large should protected areas be? Bull Mar Sci 6:745-757

> Walters C, Hilborn R, Parrish R (2007) An equilibrium model for predicting the efficacy of marine protected areas in coastal environments. Can J Fish Aquat Sci 64: 1009-1018

- Willis TJ, Millar RB, Babcock RC, Tolimieri N (2003) Burdens of evidence and the benefits of marine reserves: putting Descartes before des horse? Environ Conserv 30:97-103

> Zeller D, Stoutes SL, Russ GR (2003) Movements of reef fishes across marine reserve boundaries: effects of manipulating a density gradient. Mar Ecol Prog Ser 254: $269-280$

Submitted: August 10, 2009; Accepted: November 15, 2009 Proofs received from author(s): February 4, 2010 